\title{
FAIX, Gerhard, REICHERT, Folker, Eberhard im Bart und die Wallfahrt nach Jerusalem im späten Mittelalter
}

\section{Pierre Monnet}

\section{OpenEdition}

\section{Journals}

Édition électronique

URL : http://journals.openedition.org/ifha/1359

DOI : 10.4000/ifha.1359

ISSN : 2198-8943

Éditeur

IFRA - Institut franco-allemand (sciences historiques et sociales)

Référence électronique

Pierre Monnet, «FAIX, Gerhard, REICHERT, Folker, Eberhard im Bart und die Wallfahrt nach Jerusalem im späten Mittelalter », Revue de l'IFHA [En ligne], Date de recension, mis en ligne le 01 janvier 1999, consulté le 22 septembre 2020. URL : http://journals.openedition.org/ifha/1359 ; DOI : https://doi.org/ 10.4000/ifha.1359

Ce document a été généré automatiquement le 22 septembre 2020.

(C)IFHA 
FAIX, Gerhard, REICHERT, Folker, Eberhard im Bart und die Wallfahrt nach Jerusalem im späten Mittelalter

Pierre Monnet 
1 Le pèlerinage qu'effectua Eberhard im Bart (1445-1496) à Jérusalem en 1468 constitua un tournant dans la vie de ce jeune comte, fondateur de l'université de Tübingen en 1477 et devenu le premier duc de Wurtemberg en 1495 lors de la diète de Worms. De ce voyage subsistent non seulement une relation rédigée par son médecin, Johannes Münsinger, originaire d'Ulm et compagnon de voyage du prince, mais également le récit d'un autre pèlerin, Anselm von Eyb, mais encore le calendrier de voyage de Eberhard en personne, la liste des cadeaux rapportés de Terre Sainte par le comte, ainsi que les dispositions adoptées par le prince en son absence. Pour la première fois cet ensemble de témoignages est publié, accompagné de notes critiques, de plans et d'une liste des compagnons du comte. Trois contributions replacent ce pèlerinage dans la tradition des voyages médiévaux en Terre Sainte, dans le contexte de l'exercice du pouvoir dans une principauté allemande de la fin du Moyen Âge et tentent d'écrire une histoire de la réception de ce pèlerinage entre légendes et reconstructions postérieures. En effet, dès le XVIe s. s'est établie la tradition du surnom »barbu« du comte puis duc Eberhard (Im Bart, mot à mot en barbe). Ce surnom, dit-on, proviendrait du vœu prononcé par Eberhard de porter la barbe traditionnelle des pèlerins au retour de Jérusalem. Pourtant, aucun texte, aucune illustration du XVe s. contemporaine du prince ne fait allusion à cette association entre la barbe et le voyage en Terre Sainte. Cette question et d'autres, telles que la prétendue et en réalité fausse adoption par Eberhard du palmier dans les attributs de sa maison ou bien sur les fresques de ses châteaux ou encore la légendaire plantation d'aubépines dans ses jardins, font l'objet d'une passionnante mise au point ouvrant sur une véritable archéologie symbolique, mais reconstruite pour les besoins des siècles ultérieurs, du retour de pèlerinage princier: il n'en fut pas autrement pour un roi comme saint Louis. 